\title{
Mitología en las cosmovisiones Izalqueñas: universo simbólico de nahuales y contra nahuales
}

\author{
Mythology in the Izalco cosmovisions: \\ A symbolic universe of nahuales and contra nahuales* \\ (*those who do not follow the traditions of nahuales) \\ DOI: https://doi.org/10.5377/koot.v0i11.10739 \\ URI: http://hdl.handle.net/11298/1195
}
Lic. Miguel Ángel Hernández Vásquez Antropólogo y docente investigador Universidad Tecnológica de El Salvador miguelangeles79@gmail.com Fecha de aceptación: noviembre 2019 https://orcid.org/0000-0002-2945-4722 Resumen

La mitología es parte fundamental en las cosmovisiones de la especie humana, en donde se ubican la fundación de los pueblos originarios y su desarrollo evolutivo, en el universo simbólico que condensa sus paradigmas. En ese sentido, el presente artículo es parte de los acápites de los hallazgos del trabajo de tesis titulado "Cosmovisiones locales: tradiciones, costumbres y oralitura en las cofradías izalqueñas" para optar al grado de Licenciado en Antropología por la Universidad Tecnológica de El Salvador. Por lo consiguiente, uno de los objetivos específicos fue inferir, a través de la oralitura izalqueña, la presencia de mitos fundacionales y de creación presentes en las cofradías indígenas de Izalco en torno al relativismo lingüístico.

Dicho proceso de tesis de grado se realizó en el periodo comprendido de marzo a noviembre de 2018, en el casco urbano de la ciudad de Izalco, en donde, a través de las siguientes técnicas del método etnográfico el rapport, la entrevista guiada y no dirigida, se realizó el levantamiento de datos cualitativos en sesiones de trabajo con los mayordomos Alonso García, de la cofradía "Padre Eterno", y don Lipe Pilia Chile, de la cofradía de San Francisco de Asís, así como con Miguel Ángel Palma Gómez, touroperador izalqueño.

Palabras clave: Izalco, Sonsonate, El Salvador - Religión y mitología. Mitología indígena - Izalco, Sonsonate, El Salvador. Izalco, Sonsonate, El Salvador - Vida social y costumbres. Antropología social - Izalco, Sonsonate, El Salvador. 


\begin{abstract}
Abstrac
Mythology is an essential part in the worldview of the human race. It is here where the basis of the original peoples and their evolutionary development are found: in the symbolic universe that concentrates its paradigms. In this sense, this article is part of the findings of the thesis work entitled: "Local worldviews: traditions, customs and oral literature in the cofradias (brotherhoods) from Izalco", to obtain the Bachelor's degree in Anthropology from Universidad Tecnológica de El Salvador. One of the specific objectives was to infer the presence of the foundational myths on human creation through the oral literature from Izalco around linguistic relativism, as found in the indigenous cofradias in this city. This thesis work was conducted between march and November 2018, in the urban area of the city of Izalco. In order to collect qualitative data, the following techniques from the ethnographic method were used: the rapport, interviews--both guided and not guided--. These instruments were used with the mayordomos (religious administrator) Alonso García, from the "Padre Eterno" cofradia ("Eternal Father brotherhood), and Don Lipe Pilia Chile, from the San Francisco de Asís cofradía (Saint Francis of Assisi brotherhood); they were also used to interview Miguel Ángel Palma Gómez, tour operator in Izalco.
\end{abstract}

Key words: Izalco, Sonsonate, El Salvador - Religion and mythology. Indigenous mythology - Izalco, Sonsonate, El Salvador. Izalco, Sonsonate, El Salvador - Social life and customs. Social Anthropology - Izalco, Sonsonate, El Salvador.

\title{
Introducción
}

Cada sociedad configura, a partir de sus prácticas cotidianas de manera colectiva, los pensamientos que dan soporte al sistema de creencias que une y distingue a una sociedad de otra cercana con la que comparte el universal de la religión, llevándolo asimismo a la generalidad y particularidad en la ritualidad $\mathrm{y}$ religiosidad que fundamentan dicho sistema.

Dentro de las características del mito, Mircea Eliade1 (1991) expresa lo siguiente: "cuenta una historia sagrada; relata un acontecimiento que ha tenido lugar en el tiempo primordial, el tiempo fabuloso de los comienzos. Es siempre el relato de una creación, se narra cómo algo ha sido producido, ha comenzado a ser. En suma, los mitos describen las diversas, y a veces dramáticas, irrupciones de lo sagrado (o de lo sobrenatural) en el Mundo" (p. 6). 


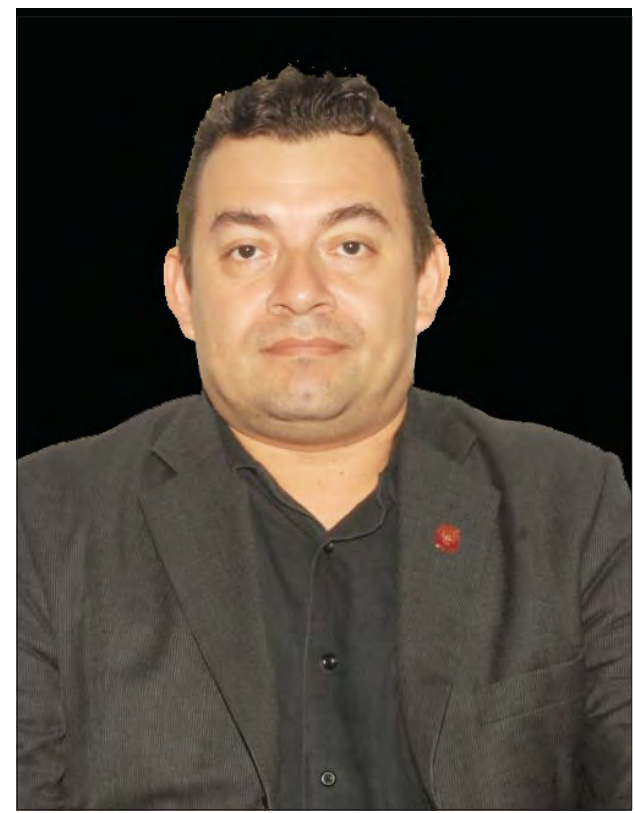

Miguel Ángel Hernández Vásquez.

Para la Antropología, es importante analizar los mitos fundacionales y de creación para descodificar los significados que guardan en la cosmovisión local de una determinada etnia en estudio. En ese sentido, Mircea Eliade ${ }^{2}$ (1991) define: "El mito sólo es tardío en cuanto formula: pero el contenido es arcaico y se refiere a sacramentos, es decir, a actos que presuponen una realidad absoluta, extrahumana...Mito del eterno retorno" (p. 7).

\section{Desarrollo}

\section{La Cuyancúa: nahual de Izalco}

Dos épocas de vida, entre la resequedad de la tierra y la fertilidad de la tierra en la época lluviosa, han marcado desde nuestros ancestros una serie de interpretaciones del cosmos, de lo que es intrínseco en el universo del ser humano, y lo extrínseco, que en la vida sociedad adquiere matices que configuran lo tangible e intangible de sus pensamientos en la cultura material e inmaterial, denotando su patrimonio natural y cultural, estrechamente ligado a la vida física y espiritual. En ese sentido, uno de los seres mitológicos que anuncian la época de preñez de la tierra es la Cuyancúa, que es para los izalqueños su patrimonio cultural, asociado también al natural, el cual se expresa a continuación:

1 Fuente: Elíade, M. (1991). Mitoy Realidad. Barcelona: Labor. p. 6.

2 Ibid.p. 7. 
La historia que más nos contaban era que cuando se acercaba el invierno, que ya empezaba a llover, la gente escuchaba en la zona de Atecozol, que es una zona muy boscosa y que está en un lugar bastante como alto de la zona de Izalco, entonces, cuando se escuchaba como un chillido de siembra, que era como un zumbido; y la gente decía que ya había chillado la Siguanaba, y que ya iba a empezar el invierno. Entonces, una semana después, empezaba a llover. Igual cuando estaba lloviendo bastante fuerte y se escuchaba el chillido de la Cuyancúa, que era porque iba a ver temporal. Bien la gente decía "hoy está chillando la Cuyancúa, es porque va a ver un temporal", decían, y cabal, se extendía el invierno en ese tiempo... También cuando ya llegaba la hora de determinarse el invierno. Unos días antes que se terminará el invierno, la época del invierno, este ser que aparecía en las quebradas en los ríos, que no solo era una, sino que se juntaban varias, también chillaban y eso daba. La gente ya sabía que con ese chillido ya terminaba el invierno. Como te mencionaba, Atecozol está en un área bien alta y tiene bastantes árboles; genera un eco, bastante eco. Entonces, la gente cabal escuchaba en todo el mundo; el centro del municipio escuchaba el chillido de la Cuyancúa.

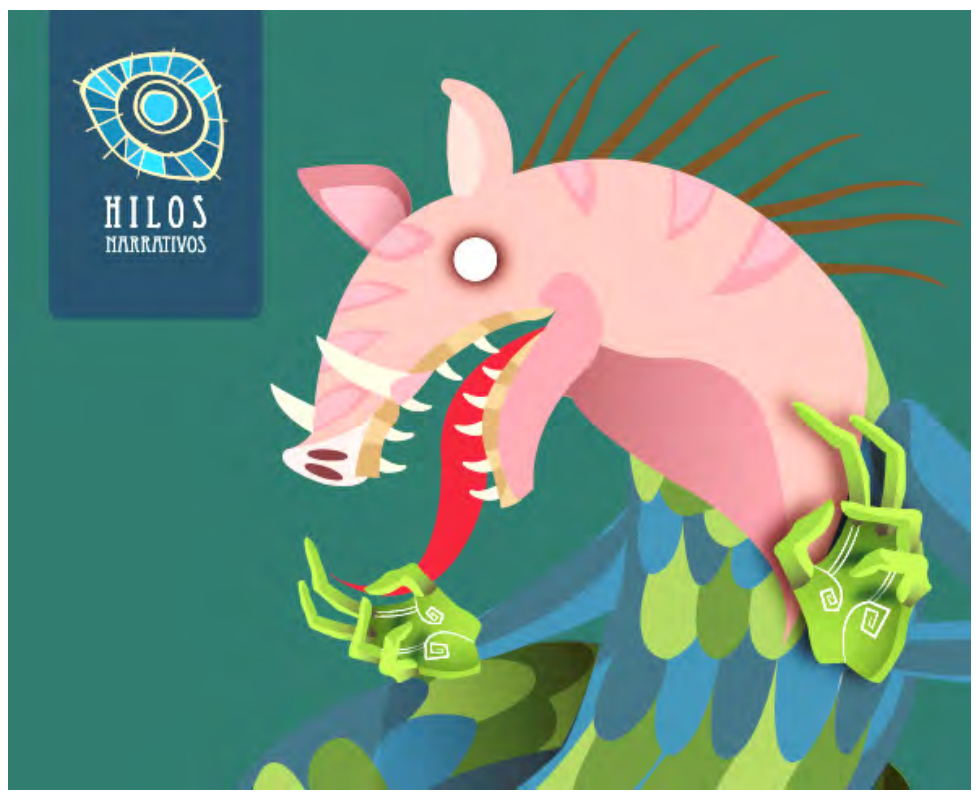

Figura 1. Reinterpretación de la Cuyancúa, por parte del arqueólogo salvadoreño Federico Paredes, retomada de: https://federicostories.blogspot.com/2017/11/the-cuyancua.html 


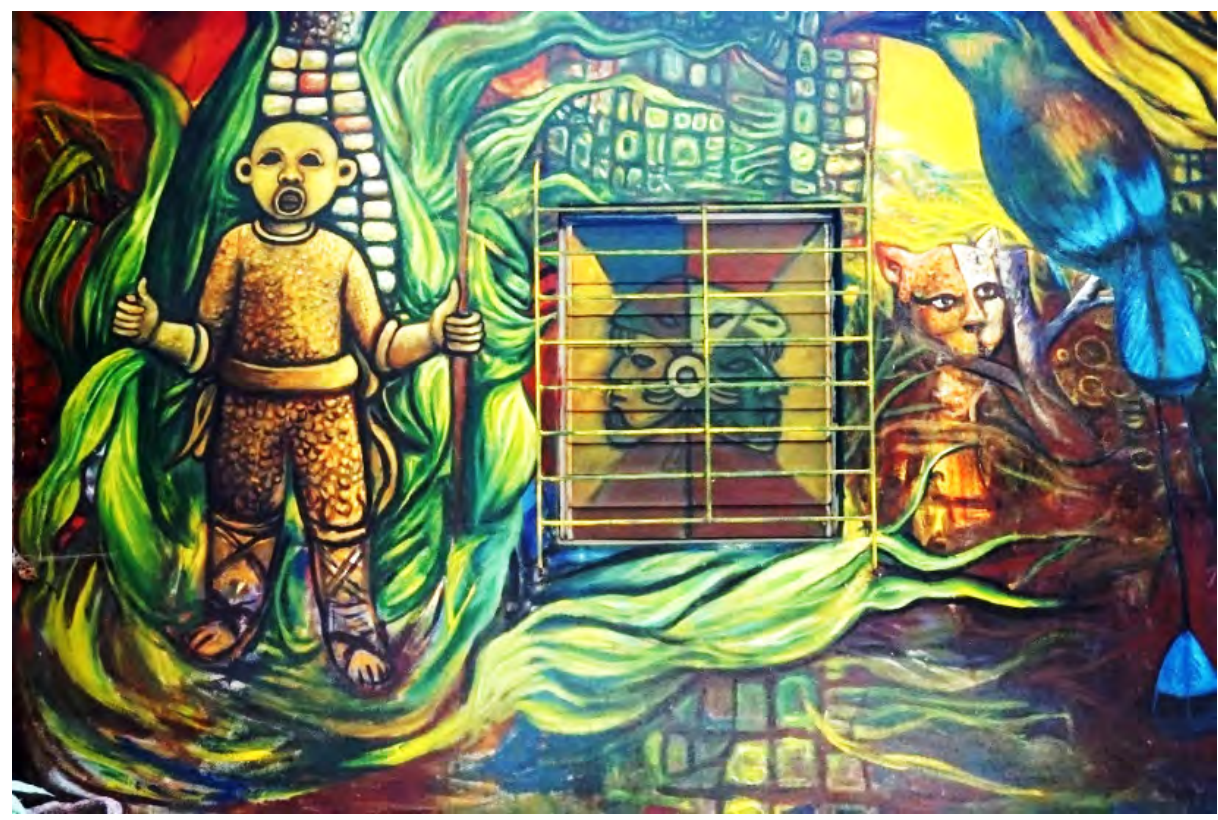

Figura 2. Mural de la "Fertilidad" en donde se retoma la iconografía del Xipetotec, mural elaborado por el Antropólogo Álvaro Sermeño, ubicado en una pared externa de su vivienda. Fotografía tomada por el investigador.

Por analogía, este ser mitológico puede trasladar al lector a la imagen del señor de la primavera, el Xipetotec, considerado una deidad en el mundo Occidental por su morfología antropomorfa. Sin embargo, al analizar dicha deidad se puede observar, como muy bien lo ha analizado el antropólogo Alvaro Sermeño, la forma de cántaro en su cabeza, las azas que definen las orejas de la cabeza del Xipe, el cual está invertido, como vaciando o proporcionando al ser humano el vital líquido. Finalmente, el cuerpo, en su tronco y extremidades superiores e inferiores, representan la semilla fertilizada del maíz, ya que dichas partes forman el grano y el olote, en su morfología. 


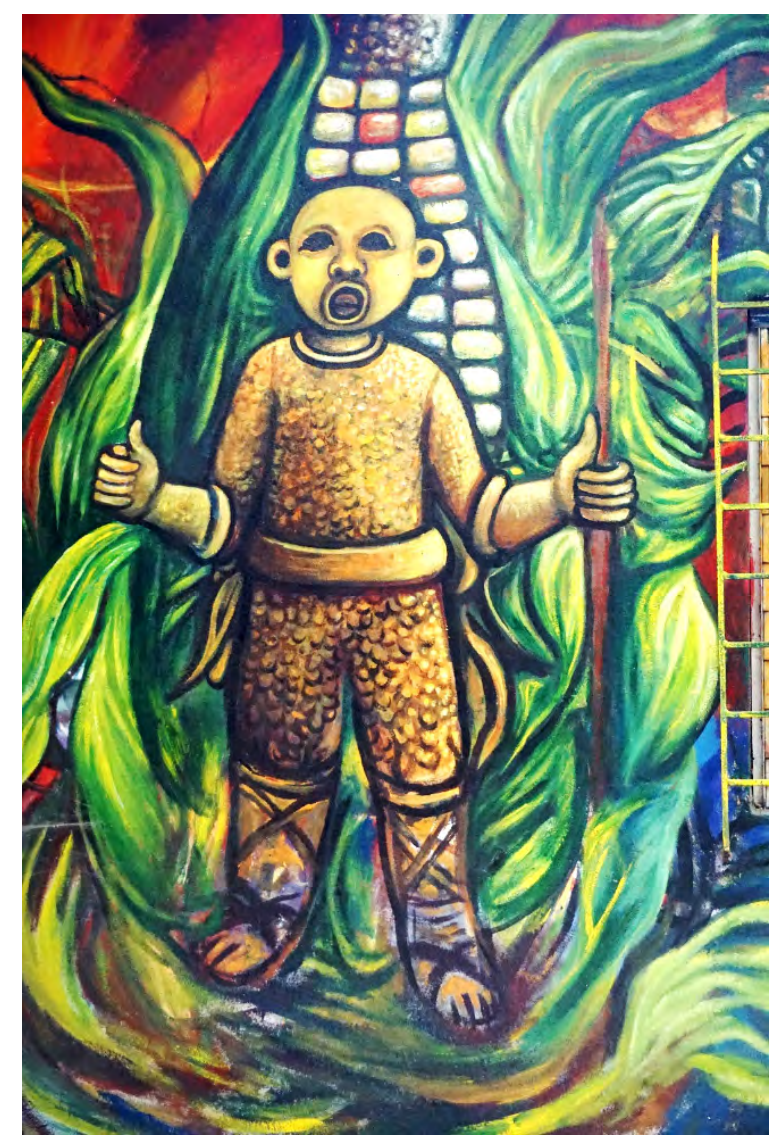

Figura 3. Reinterpretación del Xipetotec, por parte del Antropólogo Álvaro Sermeño; en donde se aprecia la escama del olote, símbolo de fertilidad como parte del ritual de la fecundidad o preñez de la Madre Tierra. Mural ubicado en una pared externa de la casa de habitación de Sermeño. Fotografía tomada por el investigador.

Ambos la Cuyancúa y el Xipetotec, son los que anuncian el inicio de la época seca, en donde el alimento es más escaso, y la llegada del invierno que anuncia la preñez de la tierra, y por ende la abundancia del alimento.

Sin embargo, la era digital, dichos elementos místicos pasan desapercibidos entre las nuevas generaciones, debido al impacto psicológico, de las redes sociales en el ciberespacio, quienes pasan sumergidas en su mayor parte del tiempo en temas coyunturales; colocando una venda en la interpretación que hacen de las realidades presentes. Todo esto en detrimento del equilibrio que se mantuvo en el pasado ancestral entre el ser humano y su medio ambiente. 
Siguiendo con el análisis de la mitología nahua pipil, Guzmán Palma, comparte el análisis de la serpiente en la morfología de la Cuyancúa:

La serpiente está bien representada desde la cultura maya, con Quetzalcóatl toda esa parte de la cultura como una divinidad, relacionada con la productividad con la tierra, y también con la parte como, por decirlo así éste de un animal que no se puede ver, animal que es rápido, que no se puede agarrar...entonces la parte de la serpiente la gente lo ha relacionado con eso, porque muchas veces la gente escuchaba el sonido, pero nunca lograban ver, escuchaban que la Cuyancúa hacia el sonido, pero nunca lograban ver, pero sólo escuchamos el chapoteo en la el agua decían, ya porque la de la Cuyancúa, había pasado, donde había escarbado, pero no lo lograban ver, entonces esa parte de la serpiente relacionado con ese sentido, con un animal arisco.

Es importante recalcar que la Cuyancúa es el nahual de los Izalcos, dentro de su mitología nahua pipil, por lo que es importante destacar que significa el termino:

Nahualli es un término náhuatl que originalmente se usó para designar dos conceptos principales: En primer lugar, este se refiere a una suerte de doble o alter ego animal que se encuentra tan estrechamente unido al destino humano que su muerte tiende a implicar la destrucción de la persona. En segundo, nahualli alude a cierta clase de especialista ritual caracterizado por su capacidad de cambiar de forma a voluntad (Martínez González, 2007, p. 189).

Por su parte, fray Alonso de Molina registra la voz náhuatl nantli como 'madre', y fray Bernardino de Sahagún refiere que los nahuas llamaban Tonantzin (es decir, 'Nuestra madrecita') a la 'madre de los dioses' (Montemayor, 2007), esto haciendo alusión al sincretismo entre lo indígena y lo español, en la imagen de la Virgen de Guadalupe en México; por lo cual, el autor infiere que seguían adorando a la antigua Tonantzin. Sahagún registra nantlalli como 'tierra madre', de tlalli, 'tierra', y nantli, 'madre'. Molina incluye nanyotl como 'matriz' (también significa 'maternidad', agregó Rémi Siméon citado en Montemayor, 2007). Sin embargo, el elemento dual o hermafrodita se ve reflejado también en el nahual. Según Montemayor (2007), al igual que con tahtli, se forma el familiar tatahtli, de cuyo acortamiento proviene 'tata'; del familiar de nantli, nanahtli, se forma 'nana'; y sigue nantli, que significa, primordialmente, 'madre', por extensión 'abuela', y, en ciertos estratos sociales, 'nodriza' (p. 1). 


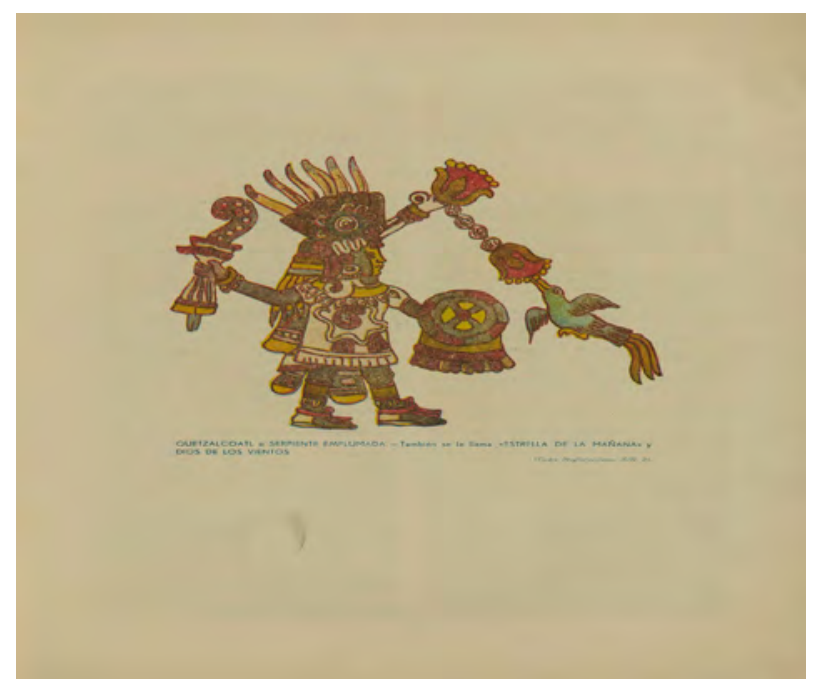

Figura 4. Quetzalcóatl o serpiente emplumada. - También se le llama «estrella de la mañana» y dios de los vientos (Codex Magliabecchiano XIH. 3), retomada de María de Baratta (1951) en su libro Cuzcatlán típico : ensayo sobre etnofonía de El Salvador : folklore, folkwisa y folkway. Primera parte.

Hablar del nahualismo es hablar de seres protectores que conducen al ser humano a lo largo de su vida a una serie de emociones, sensaciones, sentimientos de arraigo, de etnicidad en los que esta implícito los siguientes elementos:

Para el ser humano, la realidad material es conceptualmente inalcanzable; sólo tenemos acceso a los objetos y acontecimientos a través de las representaciones que de ellos nos hacemos, pues la representación "no es el reflejo en el espíritu de una realidad externa perfectamente acabada, sino una remodelación, una verdadera construcción mental del objeto, concebido como inseparable de la actividad simbólica del sujeto" (Herzlich: 1972, 306, citado en Martínez González, R., 2016, p.11).

Sin embargo, existe una dualidad en los nahuales, que según María de Baratta (1951), lo destaca a continuación:

Una de las costumbres más arraigadas, a pesar de la vigilancia de las autoridades, es el «Nahualismo», la brujería, hechizos, maleficios, curanderismo y muchas otras prácticas de lo más absurdo, que se hallan aún ahora en pleno siglo XX muy extendidas en todo el territorio de Cuzcatlán y también en todos los países de Indo-América. Pero de todas las supersticiones 
de nuestros indios, sin duda la más curiosa y más fuerte en su tradición era y es el «Nahualismo» (p.263).

En el fragmento anterior es notable el nivel de etnocentrismo, propio de la primera mitad del siglo XX en las elites criollas y ladinas, en la cual estuvo inmersa María de Baratta; por tal razón cuando la investigadora del folklor salvadoreño, utiliza el peyorativo de "absurdo" expone la realidad que la rodeaba, y por ende no es de extrañarse del porqué de su aseveración y postura frente al nahualismo. Desde la antropología se puede interpretar desde el dualismo simbólico y desde lo arbitrario del signo, visto asi en la lingüística estructural de Saussure (1916), quien lo ha codificado como algo arbitrario y convencional; lo cual le atribuye múltiples significados al ser observado desde diversas aristas. Esto significa que, desde el punto de vista científico, ninguna practica o manifestación sociocultural se le debe calificar utilizando cualquier clase de peyorativo, ya que el científico se debe a sus informantes claves.

\section{Los Tepéuas: los muchachos de la lluvia y del conocimiento}

Dentro de las cosmovisiones izalqueñas, la época de la cosecha está regida por una serie de entidades míticas, que inciden en la productividad de la tierra, que ha de germinar, siempre y cuando el ser humano este en equilibrio con la madre naturaleza; así como la Cuyancúa anuncia la llegada de la lluvia, para que inicie el proceso interno de germinación para los diferentes organismos activen el ciclo de vida. Dicho ciclo de vida está gobernado bajo la cosmovisión de la población náhuat-pipil por otros entes; se hace referencia a los Tepehuas, estudiados ampliamente por el antropólogo alemán Leonhard Schultze Jena en 1934, en el contexto del etnocidio en el occidente del actual territorio salvadoreño.

Schultze Jena ${ }^{3}$ destaca el significado de tepéua "El nombre dado de "Muchachos de la Lluvia", así los tepéua en Pipil, cuyo correcto plural y sustantivo es textepenámet, lo derivo del verbo ni-k-tepéua-a que significa "arrojar", "esparcir". Este es la principal actividad de estas criaturas, esparcir la lluvia sobre la tierra (p.49).

"Sahagún nos informa que también las deidades de la montaña, que de argamasa eran moldeados en miniatura, el tepictoton de los Aztecas, se contaban entre los Dioses de la Lluvia" (Schultze Jena, 1977: p.49). Así mismo la relación entre el volcán de Izalco, y el elemento del agua, se destaca en el siguiente fragmento:

3 Schultze Jena, L. (1977). Mitos y leyendas de los pipiles de Izalco. San Salvador: Cuscatlán. Pág.49 
Una relación de ideas con tépet $=$ cerro, en cuya cima recogen copos de nubes de lluvia, tendría en las acepciones del Quiché su relación colateral. En raíces se impide una relación de contraste así: tepeu (gramaticalmente, verbo intransitivo tepeu- $i=$ bajar en cantidades) que es la raíz para esparcir (en comparación), opuesto a tepe que es la raíz para "cerro". Yo no encuentro que este examen resista del todo una relación de ideas entre "cerro — duro - pequeño". (Schultze Jena, 1977: p.49)

Por su parte Alonso García (2018), hace referencia a como dichos personajes, previenen o anuncian los días aciagos haciendo alusión a las cosmovisiones mayas, o de maleficios, cuando la relación entre el ser humano y el medio ambiente, no ha resultado muy equilibrada. Lo anterior, se contextualiza, cuando en las cosechas, sobre todo en el máiz, aparecen unos granos negros; tal como se decribe Alonso García (2018), a continuación:

Hace 60 años, nosotros teníamos una ritualidad de los Tepéuas, más que todo en este mes de julio, cuando aquí eran ranchos metidos en las montañas, todo esto eran montañas, aquí estaba un rancho donde vivió mi abuelita Anita Putun, aquí les dejo a los hijos, y yo compre... entonces, no es lo mismo habitar en un territorio, que vivir en un patio... porque en el mes de julio, había la creencia, que ya se cabo eso, la madre naturaleza y la madre tierra ha venido a cobrar justicia, porque, en este mes que decimos el mes del Jilote...algunos afirman que los han visto, mi mamá afirmaba que había visto el mito del Tepéua... entonces qué es lo que pasaba, que se veía que venía una tormenta la haz de los árboles, y una nublazón negra, y que los palos zumbaban... y como era una creencia, una realidad le da ritualidad que ella hacía es sacar el Tol y sonarlo (el caracol) que la creencia esta exacta que, se iba de paso.

Por los apuntes de un Franciscano del tiempo de la Conquista, sabemos que el Dios de la Lluvia había creado muchos pequeños ayudantes -"para llover crió muchos ministros pequeños de cuerpo" en donde la funcionalidad que ejecutaba según Schultze Jena (1977) los análisis, que hizo de estos seres mitológicos en los pipiles de Izalcos era "sacar el agua de los cubetes que estaban en el patio de su casa, para que se esparciera como lluvia sobre la tierra" (p.49). 


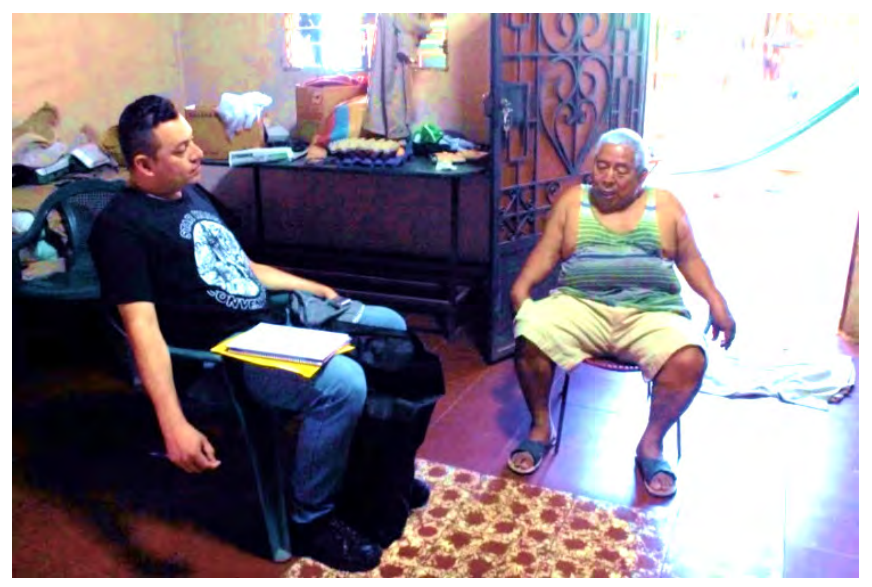

Figura 5. Entrevista guiada con Alonso García, mayordomo de la cofradía de Padre Eterno y María Asunción. Fotografía tomada por Miguel Ángel Najo Latin, el día 9 de julio de 2018.

Sigue Alonso García (2018), con el relato mitológico de los Tepéuas:

Pero como ahora no llueve, antes sí llovía, eran unas tormentas... vamos hablar de nuestro propio medio, itene cuidado noy, porque los Tepéuas ya van a venir!! Entonces, lo que se estableció fue que solo se cultivaba el maíz, solo se cultivaba el uno pilse y el capulín, entonces aquellas milpas estaban en pleno jilote en este tiempo; entrando el elote, entonces era cuando los Tepéuas venían, a llevar los granos de maíz, a alimentarse con el maíz, entonces para mayor creencia, que no había abono, ni cosa que se le parezca, los dones así de tamaño, así de grandotes, entonces decían aquí pasaron los nanahuas o los Tepéuas...y la palabra común es, ¡aquí se cago un Tepéuas! Porque en la punta de aquella mazorca le salían búas negras (García, 2018).

Según Leonhard Schultze-Jena ${ }^{4}$ (1975), los Tepéuas, o "muchachos de la lluvia” son aquellos seres que afectan intencionalmente las cosechas, incrementando el caudal de los ríos, generando la impermeabilidad en el suelo, afectando por ende las cosechas del maíz. Dando como resultado, la aparición de las búas negras a las que hace referencia Alonso García (2018), en las puntas de las mazorcas. Por analogía en la cultura Maya se denominan "días aciagos o de mala fortuna"; describiendo dicho proceso metereologico de la siguiente manera:

4 Ibid. 
"Los Tepéuas producen truenos y granizos que dañan las cosechas.En tiempo mitico, con hachas de pedernal-machi abren la montaña para extraer el maíz. Al presente, el acto primigenio se reitera desde las nubes al golpear piedras con esas mismas hachas. Sus fragmentos que "raja[n] árboles", los hacen "arder" y "se esparcen" destructivos como "granizo" (Schultze Jena, 1977)

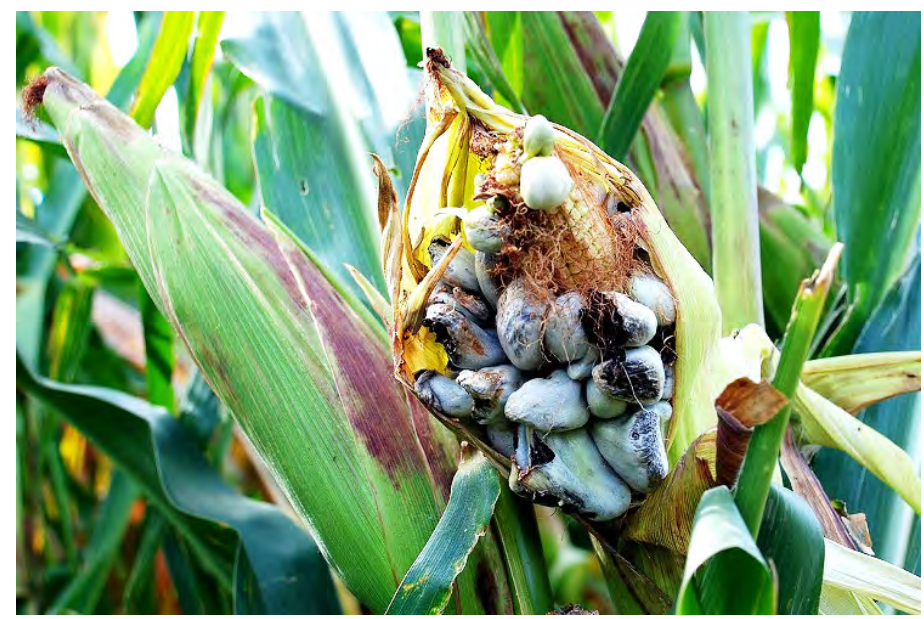

Figura 6. Las búas u hongos del huitlacoche, similar al relato de las búas descrito por Alonso García en la entrevista guiada. Imagen retomada de http://www.sobreestoyaquello. com/2017/03/huitlacoche-el-horroroso-manjar-de-los.html

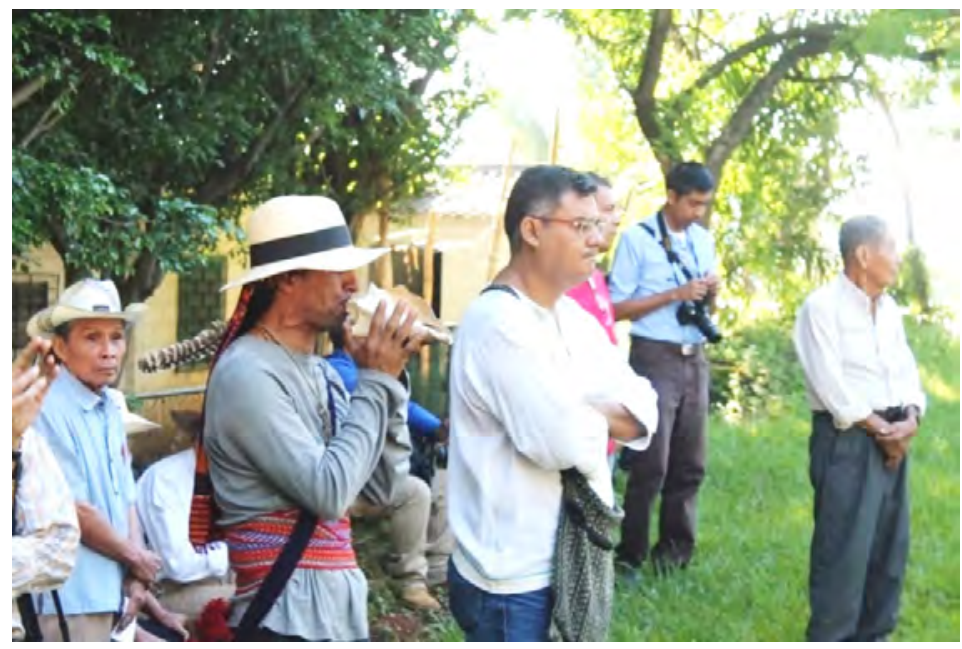

Figura 7. El sonido del Tol (caracol), en ritual Celebración del Día Internacional de los Pueblos Indígenas en Izalco. Registro fotográfico propio 
Mientras, que en la cosmovisión izalqueña, se tiene una percepción muy diferente de los Tepéuas, considerados seres sobrenaturales, relacionados con el ciclo de la vida: la lluvia para hacer germinar la semilla del maíz, y alimentar el conocimiento, en palabras de Alonso García (2018), se define:

Entonces la gente decía ... ¡aquí se cago el Tepéua! ese elote no servía, ese cortaba, se iba a buscar después de la tormenta, a los ocho días, aquí se cago el Tepéua...era una comida que se creía para adquirir sabiduría y conocimiento, venían los tatas, los abuelos, sacaban el elote, y ese grano que ahora le dicen búa, lo hacían en pupusas, y se lo daban a los jóvenes para la fertilidad, para el conocimiento y la sabiduría, por eso es que el tepehua, es un mito, lo que ahora en la actualidad se llama extraterrestre, mucha gente cree y considera que los extraterrestres bajaron, lo que en la náhuat son Tepéuas, $y$, creen que dejaron genes por todos lados... porque aquí lamentablemente dicen que sus raíces son de Tepéuas, y el señor ya se está muriendo, ayer me contaron que ya no responde.

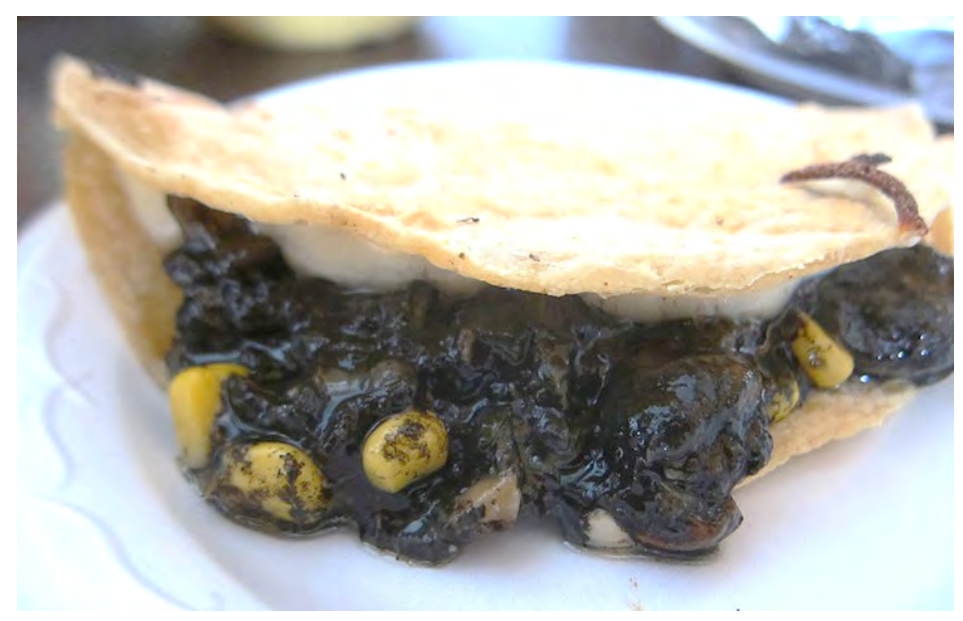

Figura 8. Los hongos del huitlacoche preparados en la típica quesadilla mexicana. Imagen retomada de http:/www.sobreestoyaquello.com/2017/03/huitlacoche-el-horrorosomanjar-de-los.html

Estos seres mitológicos, considerados no humanos o extraterrestres, se quedaron a convivir con los izalqueños, mezclándose con ellos, para generar descendencia y fortalecer la sabiduría en las nuevas generaciones, como muy bien lo describe Alonso García (2018), en el siguiente fragmento: 
Vamos a juzgar la vida ajena, el señor, el rostro, no es de humano, se le ve... aquí teníamos una persona que si usted le tomaba una foto, no le volvía hablar y era su peor enemigo, ya falleció, esos eran hijos de Tepéuas...al grano le llamaban nanahuas, ahora le dicen búas... pero eso se le llama nanahuas, y era el excremento del tepehua... se consumía para que el hombre o la mujer, tuviera una buena fertilidad y adquiría el conocimiento... y tener una buena descendencia... pero Lara Martínez, él no sabe ni lo que está escribiendo... yo soy amigo de un alemán, vino a participar en las fiestas tradicionales del sincretismo, y le tomo fotos a esas persona (él es el que está falleciendo y el otro señor), a los ocho meses me escribió y me dijo que era confirmado que, eran hijos de los Tepéuas... pero ya no me escribió el señor... pero me confirmo que tenían esa diferencia en el rostro, y eran pequeños... entonces me confirmo eso.

La presencia alienígena, considerados "alienígenas ancestrales" por la ufología o pseudociencia; coincide con los relatos de los antiguos pobladores izalqueños, que describen a estos seres, o entidades, como los encargados de anunciar el proceso cíclico de vida en la primavera, durante la época lluviosa, que, ya germinada la tierra, los jilotes, comunicaban a nivel visual, el alimento que pronto han de alimentar el cuerpo y el alma, al compensar las jornadas laborales de sus agricultores.

Estos seres contaban con mucho misticismo en el imaginario colectivo de los náhuat-pipiles, quienes, les otorgaban a las búas el medio para transmitir sabiduría a las nuevas generaciones de hombres y mujeres dentro de la cosmovisión izalqueña; el alimento espiritual que se obtiene de las búas negras o huitlacoche representa la gnosis para los izalqueños y por ende el mundo físico que los rodea, permiten que los nahuales cada año interactúen entre sí para que la Cuyancúa anuncie la llegada de las tormentas, y es ahí donde el Xipetotec hace su trabajo para preñar la tierra (tal en náhuat - tlalli en náhuatl mexicano), con la llegada del invierno. Frente a este escenario los Tepéuas (muchachos de la lluvia) se encargan de generar el movimiento cósmico para que el Sol (tunaltunatiu), acelere la depresión atmosférica, produciendo los truenos y granizos en la montaña, para que después de terminada la tormenta se revitalice la vida en su entorno natural. Obteniéndose como resultado el alimento físico que nutre la vida del ser humano. 


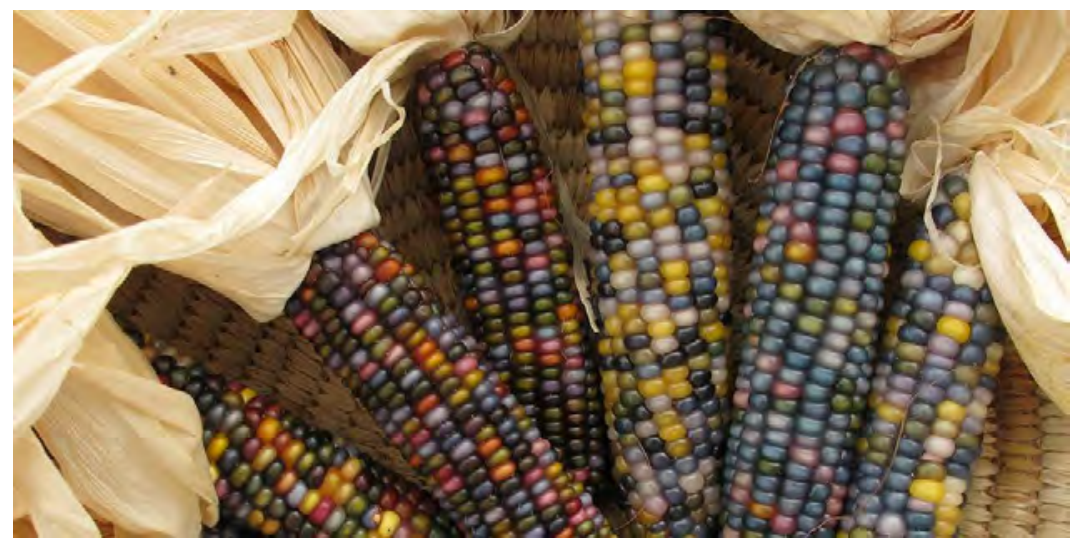

Figura 10. Cromática e hibridación de la semilla natural del maíz en los pueblos indígenas, tomada de https://www.animalgourmet.com/2014/09/30/glass-gem-corn-el-maiz-de-los-mil-yun-colores/

\section{El Guashake una entidad nocturna; como un contra Nahual.}

En el imaginario colectivo salvadoreño, es normal escuchar la frase "Ya te llevó la que no te trajo", asi como el dicho "el que anda entre la miel algo se le pega"; frases claras que describen la naturaleza del ser humano, cuando se trata de desafiar las normas establecidas en la sociedad a la cual pertenece como sujeto, y que, como individuo desafía constantemente, hasta lograr lo que muy bien sustenta el dicho: "tanto va el cántaro al río que termina quebrándose". En ese sentido se retoman los recuerdos de adultez de Don Lipe Pilia Chile (2018), quien recuerda muy bien su periodo de consumo desmedido de alcohol; el cual le generó una serie de vivencias paranormales, o de sustos, como se dice en el lenguaje popular salvadoreño; una de esas vivencias se presenta a continuación:

El Guashake es un animal.... plumudo como una chumpa... si no es suyo, para usted, solo lo mira y ay se va...pero si lo torella, compóngase...y esa vez, a mí nunca me han asustado, cosas así, pasé mi juventud...yo cuando chupaba, salía a las doce de la noche, de la cantina, solo me envainaba mi corbo aquí, y la lámpara, eso andaba cargando... lo que sí, que yo antes ya había comprado, dos crucifijos así, en San Antonio, dos Cristos...y allá me los bendijo el cura, yo lo compré en la puerta así del atrio, y cuando yo chupaba que salía medianoche, lo agarraba, lo ponía uno adelante y otro atrás...el corbo y lámpara. 
Existe un dicho popular que dice: "andando bueno y sano a uno le pasa cualquier cosa, por el contrario, andando bolo, no pasa nada"; sin embargo, hay excepciones, tal como le sucedió a Don Lipe Pilia (2018), quien compartió dicha experiencia de vida:

Cuando yo chupaba, yo salía a las once y media, o a las doce, sólo un amigo que vivía ahí, se llamaba Antonio Velado, tocaba marimba, él era el único alero que tenía, y yo le iba a hablar... ohhhh, vamos! a vamos, él sin pisto, él atenido que yo, a mí me fiaban y me vendían... fuimos a las 11 y media de la mañana, y la señora allá abajo le había pagado, tres pesos de chicha, eran doce botellas, porque 25 la botella... nos bebimos seis, la mitad, a la una y media, eran ....achís, vamos a andar arriba, me dijo él, las casas, están solas, ah!!! vamos pues!!! cuando uno patudo, ehhhh le vale verga!!!.ahí un familiar, la señora se había levantado, con una su candelita así, chas baje yo... y aquel se jue....este solar, aquí era solo, eso era solo, unas parvas de adobe habían ahí, un charral así de ese porte... (un metro y medio) cuando llegue ahí... ya está amaneciendo, me dijo...que andas haciendo vooooos!!!!, me dijo, si es noche!!! ¡Ja!! que veo tenes la luz prendida... ahhh las pulgas!, me dijo: ¡estoy matando pulgas! me dijo la señora, como el tahuipante así, en toldo de vara, se miraba... anda acóstate!!!, me dijo...ya me voy pues ay nos vemos, salí ay, allá iba ve, donde está la puerta de la casa... pero la calle ésta!! mire llena de piedras, no eran ni calles, sino que callejones...y quizás lo más que eran de ancho, el poste y una carreta, es lo más que cabían, como antes solo carretas y bestia, era el transporte cuando yo iba, no habían las luces o piedras fijas, vaya madre!! a ver quién está cagando por ahí...echeeee por todo pajo, poh,poh,... tetuntes.

Siguiendo con el relato de Don Lipe, el primer escenario a enfrentar ante una situación como la anterior, es la incertidumbre, luego el escepticismo, seguido de un cuestionamiento del porque suceden las cosas en momentos determinados, como, por ejemplo: alguien que viene de departir con sus cheros alcohólicos, y piensa que nada le pasará en el camino de regreso a casa, y que todo se mantendrá en la "normalidad de siempre", muy a pesar de las advertencias que hacen los abuelitos y abuelitas, en el hecho de andar trasnochando, que todo puede pasar, hasta lo imaginable.

Retomando los registros históricos y etnológicos sobre este personaje mítico en la población náhuat-pipil se hace referencia al fragmento de oralitura que Roque 
(2004; 46), registro en náhuat y luego ha sido traducido en español por Lara Martínez \& McCallister (2012), a continuación:

\begin{tabular}{|c|c|}
\hline Texto en náhuat & Texto en español \\
\hline $\begin{array}{l}\text { Mujtiluía úhti ta Tsuntsúnat } \\
\text { tíkne pága úshtu ta San Pedro } \\
\text { kualguía se guasháke } \\
\text { guen tejémet tikuígat shúmpe } \\
\text { uan máchet pálti chajchalúa ne guasháke. } \\
\text { Ne ueshkininu ne shúmpe ten gátik } \\
\text { uan guísat ne guasháke kutujtúgat } \\
\text { ga ne kójtan. }\end{array}$ & $\begin{array}{l}\text { Por el antiguo camino de Sonsonate } \\
\text { En la cima de la barranca de San Pedro } \\
\text { salía un guashaque; } \\
\text { pero nosotros llevábamos sombrero } \\
\text { y machete para golpear al guashaque. } \\
\text { Al aletazo cayó el sombrero boca arriba } \\
\text { y salió el guashaque despavorido por la montaña. }\end{array}$ \\
\hline
\end{tabular}

Figura 11. Cuadro de elaboración propia y retomado de Lara Martínez \& McCallister (2012), El legado náhuat-pipil de María de Baratta.

Por su parte María de Baratta ${ }^{5}$ (1951), en su libro Cuzcatlán típico: ensayo sobre etnofonía de El Salvador: folklore, folkwisa y folkway, menciona la figura de otro ser mitologico denominado el Guashaco, quien describe en el siguiente registro de oralitura, que la folklorista registró, el cual se presenta a continuación:

Los indios de Izalco, Nahuizalco, San Julián y Juayúa, tienen la creencia de un personaje de leyenda en figura de mono, que llaman: el "Guashaco". A lo mejor se ve a un grupo de indios, apostados alrededor de un rancho armados de sendos garrotes y machetes, para deshacer a leñazos, como ellos dicen, al "Guashaco". Una vez, Pedro, marido de una pobre india, la abandono, y ella decía que el "Guashaco" se lo había llevado. Tenían un hijito y este se enfermó; la pobre salía a dar voces al monte llamando a su "Pegru". Desesperada cogió a su hijo y se fue al pueblo; al atravesar la montaña le salió un mono, y la india encolerizada le grito: "!desgraciadu, no sos 'Guashaco', lu sos Pegru que me lo querés quitar lo cría, no sos 'Guashaco', sos lo maridu, ya te lu conozco, sos Pegru!"; y la pobre india salió corriendo (p. 272).

Asi mismo Don Lipe Musto (2018), menciona la figura del mono, como parte del quehacer de los brujos en Izalco, el cual se describe en el siguiente fragmento de entrevista guiada:

5 Baratta, M. d. (1951). Cuzcatlán típico: ensayo sobre etnofonía de El Salvador. San Salvador: Publicaciones del Ministerio de Cultura. 
Aquí pasaba un animal, un mico. Como antes todo eso era monte... pasaba la vereda a salir hasta allá por la ceiba, hasta el kínder... Ay pasaba de nuevo hasta salir allí, a la barranca... Una vez, sí, en el ranchito de nosotros... Estábamos cenando con la finada y mis hijos... como a las siete, siete y treinta. Oí, yo, que me le pegaron una patada a la puerta. Salí, yo, a ver. Cuando voy viendo que el mico era.... Allí iba. Cuando lo alcancé a ver, que se atravesó el cerco, “¡Jayyy — le dije yo—, te conocí quién sos vos”, sin saber quién era. Y otro día encontré al chero... "¡Puta! —me dijo- . Tenés tu valor — me dijo—. Tenés tu valorcito...”. Y le dije: “¿Y eso porque vos?”. "Te pasé fregando anoche. ¡Le di una patada a la puerta y ligerito salistes!”- — me dijo_- "A pues sí —le dije yo-. Uno no hay que ser atenido". "¡Yo soy, hombre!, no tengas pena. Cuando oigas cualquier cosa, no salgás. Yo soy. Por ahí me mantengo mientras se me llega la hora... a las doce... Me estoy arriba de tu casa. Yo te conozco a vos. ¡Somos amigos, hombre! No tengas pena. Yo, para vos no..., no te busco". Pero si me dijo "¡no salgas!”... "Ese día me afligiste, porque salistes con el corvo. Me hubieras jodido, pero yo era el culpable...". Y eso fue temprano, como a las 7:30 a 8:00.

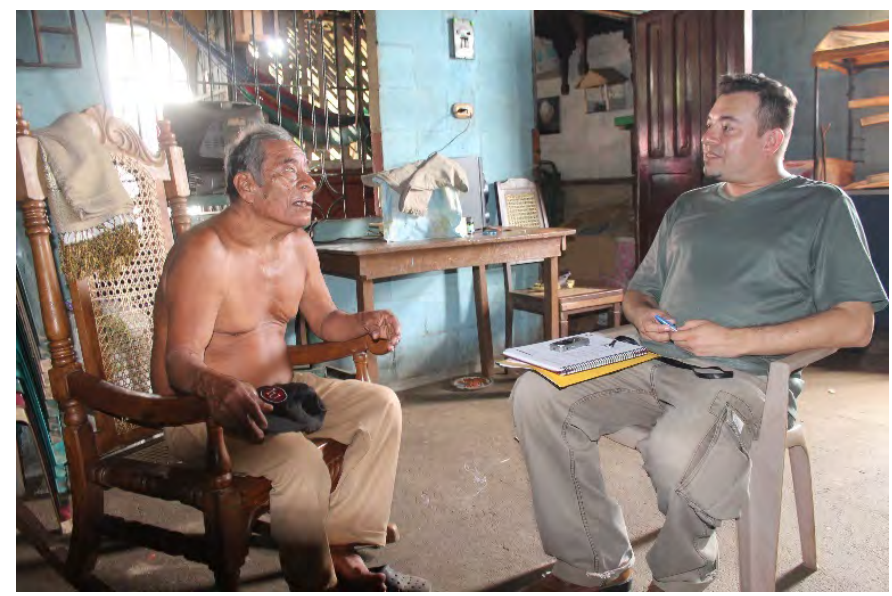

Figura 12. Proceso de entrevista guiada con Don Felipe Musto en la cofradía de Santa Lucía. Fotografía tomada el día 8 de julio del año 2018 por Francisco Santos Alvarenga, estudiante de Antropología Utec.

Este ser mitológico del Guashaco, al parecer ha servido de inspiración para los brujos de Izalco, tanto así que la figura del mono es un elemento simbólico de las transformaciones que han caracterizado a dichos sujetos encargados del manejo de conjuros, sortilegios, adivinaciones o encomiendas para hacerle un daño a otra persona considerada rival o enemigo, por quienes acuden a los 
servicios de los brujos y brujas izalqueños. Siguiendo con el relato de Don Lipe Musto (2018), el comentó:

Ay tengo la vereda; ahí paso. Y si no, se estaba ahí arriba de la lámina donde vive la otra hija... Ahí estaba rascando, tirándole arena... Una vez nos preocupamos. Me curaron tres tiros, quizás me veló el sueño. Como son picaros, sentí sueño. Me fui acostar, me dormí. Cuando al ratito paso ahí el animal... Golpetazo. Me dice la finada: “¿No sentiste el mico que pasó?”. "Mirá - le dije yo—, quizás me durmió". "Al ratito que vos te entraste, pasó. Sintió el tufoso a Jacinto. Allí pasaba, al otro lado, el gran tufaso...". Deje ir un tiro cuando salió otro vecino y me dice: "¿Qué te pasa? Oyí que tiraste". "Ay pasó un animal y me velo el sueño. ¡Busquémoslo!” —me dice-. Y él tenía su pistola allí. Ay, cuando íbamos allá, le tiramos. ¡Qué lo íbamos andar encontrando!... Pasó el terremoto, y un día lo encontré allí acostado. Como esta casa era de tejas; por allá estaba el comedor. Allí, bien dormido, arriba de la casa por el corredor, como a las 5:30, ya podía más la noche. Bien dormido estaba en la mera esquina. “ ¡Ay, jodido, te dormiste! Cuando ay salió, el jodido, en carrera para allá. ¡Tamaño animal!

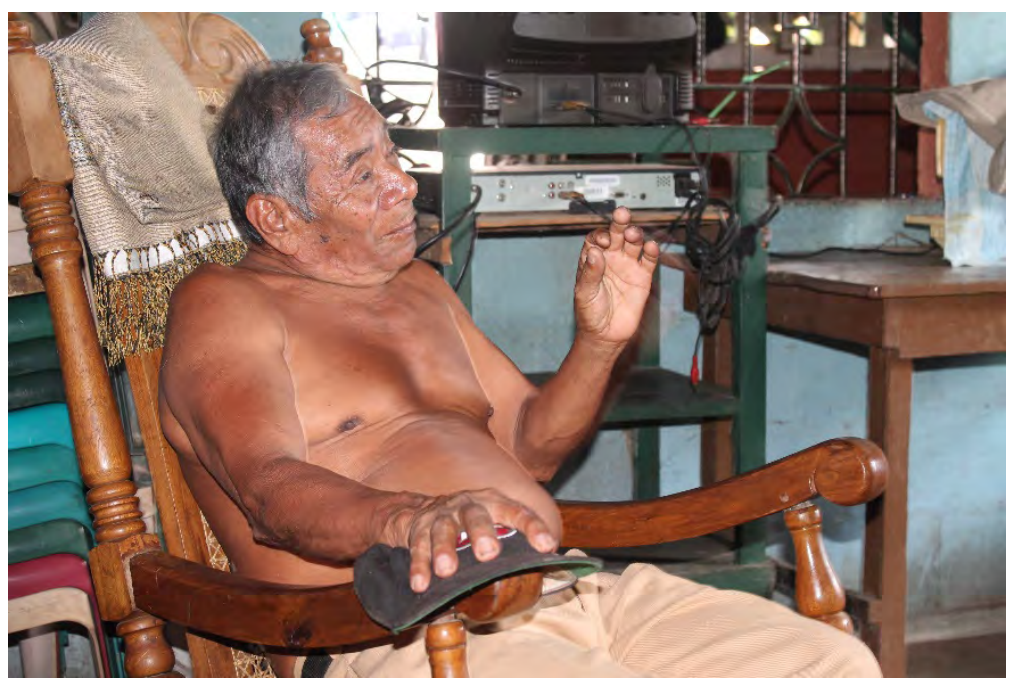

Figura 13. Proceso de entrevista guiada con Don Felipe Musto en la cofradía de Santa Lucía. Fotografía tomada el día 8 de julio del año 2018 por Francisco Santos Alvarenga, estudiante de Antropología Utec. 
En el fragmento anterior se puede apreciar el simbolismo del mono retomado por los brujos de Izalco, para hacer alguna especie de daño o maleficio a la persona que es su objetivo por encargo de un tercero. Es un universo paralelo al relato que María de Baratta registro en los años 50 al hacer referencia al ser mítico del "Guashaco" dentro del imaginario colectivo náhuat-pipil del departamento de Sonsonate, el cual pervive hasta la actualidad, en pleno siglo XXI.

Retomando la figura del Guashake, Lara Martínez \& McCallister (2012), quienes describen a este ser mitologico de la siguiente forma:

El guashaque - un ave nocturna de la magnitud de un pavo común - se complace en salir a los caminos. Quien la ve queda paralizado, cae, y el animal goza al agitar las alas sobre su víctima, produciendo en ella un sueño letárgico que puede durar largo tiempo (Biblioteca virtual: Universidad de El Salvador). Kutujtukak parece provenir de ku- "herir, lastimar, dañar" + tutul "ave". Baratta asienta que, en Izalco, Nahuizalco, San Julián y Juayúa existe la creencia en un personaje en forma de mono que se llama el Guashako, cuya semejanza lo emparienta a los Managuas, "hombres monos" (Baratta, 1951: 272).

A la media noche, emergen entre el mundo de los vivos, los entes espirituales, algunos de ellos oscuros; dichas energías espirituales pueden ocasionar situaciones adversas, al que anda en la calle parrandeando a altas horas de la noche, tal como se presenta en el siguiente fragmento de la memoria de Don Lipe Pilia (2018):

!!! quiero ver este hijueputa!!! como uno de bolo es abusivo, se dispone a cualquier cosa, saque mi corbo y con la lámpara en la lengua, ahí llegue!!!! yo que pego el achonazo!! y me quemó el poh!! y se levante el animal ahí ve, ehhhhh como que era chumpe, el hijueputa!!!yo no lo vi, pero el bolillero ordinal, habían más palos, estaba cerrado... yo venía de media rienda, poderoso el hijueputa!!!! porque cuando yo me levanté de goma!!!!! Ahhhh, me quito la goma el hijueputa!!! y salgo a ver el chero!!... oy cusuco!! asi le decía yo!! .... oyyyy, ya venís ya! ya, ipúrate y nos vamos para bajo!!, iiiPuta luego!!!, jaa!!! nombre me acaban de asustar!!! para que putas te quedas pues!! me dijo él... ¿Quién te asustó vos? ¡creo que "El Guachaque!! me quitó la fuma!!! le digo, que si me agarra de goma me gana ese hijueputa!!! así jue.....No porque, jotro como antes, que aquí había brujos no, nunca me asustaron! 
Ante el escenario adverso, las reflexiones son importantes analizar, tal como Don Pília afirma, que posterior al susto del Guachaque, él se encomendó a "Chico", el milagroso San Francisco de Asís, para lograr superar esa etapa del alcoholismo, y de esta manera cerrar esa parte de su vida; ya que gradualmente Pília afirma que dejo el vicio del alcohol, por todas las circunstancias no tan agradables que vivió en su etapa de alcohólico.

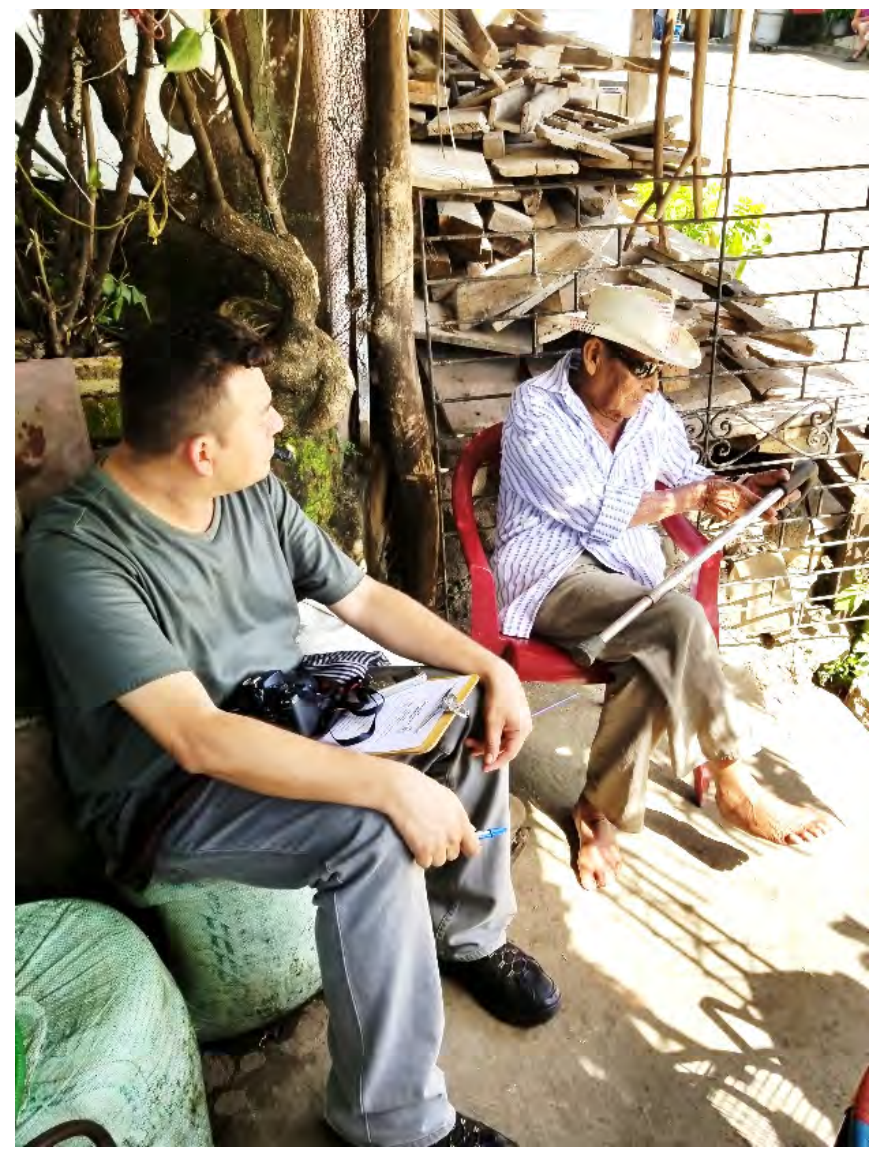

Figura 14. Proceso de entrevista guiada con Don Felipe Pilia Chile en la cofradía de San Francisco de Asís. Fotografía tomada el día 8 de julio del año 2018 por Francisco Santos Alvarenga, estudiante de Antropología Utec. 


\section{Conclusiones}

- Dentro de la oralitura resaltan los mitos etiológicos como lo son los Tepehuas, la Nanahuatzin, la Cuyancúa entre otros; los cuales están asociados a fenómenos naturales, en donde el ser humano es vulnerable, ante la adversidad de los diferentes cambios climáticos. Sin embrago, como bien dice el dicho; después de la tormenta viene la calma, y ante esa calma, el fruto de dichos eventos naturales, queda siempre una huella, la cual ayuda a seguir adelante a los Izalqueños. Se hace referencia en este caso particular a la bula, la cual codifica una dualidad entre los augurios de días de maleficio y la sabiduría del conocimiento en el alimento que se obtendrá al consumir dichos granos de maíz.

- Los elementos simbólicos indígenas están presentes en el ritual de la cosecha, cuando los mayordomos y cofrades Izalqueños, les rinden culto a las imágenes en cada festividad; esto como agradecimiento por los favores obtenidos durante el año. Cabe destacar que el elemento sacrificial, está presente en el mantenimiento de la mesa altar, en el cuido y resguardo de la imagen, para que la feligresía y cofrades puedan estar en comunicación constante con sus deidades; muy a pesar de las criticas destructivas y el desprestigio al cual son objetos los mayordomos y mayordomas de Izalco, esto no es ningún obstáculo para mantener viva la tradición y "el costumbre", éste último un elemento muy particular en la cotidianidad de los Izalqueños.

\section{Referentes bibliográficos}

Baratta de, M. (1951). Cuzcatlán típico: ensayo sobre etnofonía de El Salvador: folklore, folkwisa y folkway. San Salvador, El Salvador: Publicaciones del Ministerio de Cultura.

Clará De Guevara, C. (diciembre, 2010). Tradición oral salvadoreña. Mestizaje, religión y valores. REDICCES, 102-113.

Elíade, M. (1991). Mito y realidad. Barcelona, España: Labor.

García Canclini, N. (2001). Culturas hibridas, estrategias para entrar y salir de la modernidad. Buenos Aires, Argentina: Paidós.

Hernández Vásquez, M. (2018, marzo). La cuyancúa y las cosmovisiones izalqueñas. [Grabación de audio].

Hernández Vásquez, M. (2018, julio). El Guachaque, brujos, oracionistas y recuerdos de la mayordomías en Izalco. [Grabación de audio].

Hernández Vásquez, M. (2018, julio). La doctora de la ceguera de los izalqueños. [Grabación de audio]. 
Hernández Vásquez, M. (2018, enero). Seres mitologicos en la cosmovisión indigena. (A. Sermeño, Entrevistador).

Hernández Vásquez, M. (2018, julio). Mitología y oralitura en las cosmovisiones izalqueñas. (A. García, Entrevistador).

Lara Martínez, R. (2014). Mitos en la lengua materna de los pipiles de Izalco en El Salvador. San salvador, El Salvador: Universidad Don Bosco.

Lara Martínez, R. y McCallister, R. (2012). El legado náhuat-pipil de María de Baratta. San Salvador, El Salvador: Fundación AccesArte.

Martínez González, R. (2007). Los enredos del Diablo: o de cómo los nahuales se hicieron brujos. Relaciones, estudios de historia y sociedad, 28(111), 189-216.

Montemayor, C. (31 de julio de 2007). Notas sobre nahuatlismos. La Jornada. Recuperado de https://www.jornada.com.mx/2007/07/31/index.php? secti on $=$ cultura\&article $=\mathrm{a} 05 \mathrm{a} 1 \mathrm{cul}$

Schultze Jena, L., Menjivar Rieken, G. y Parada Fortin, A. (1977). Mitos y leyendas de los pipiles de Izalco. San Salvador, El Salvador: Cuscatlan. 


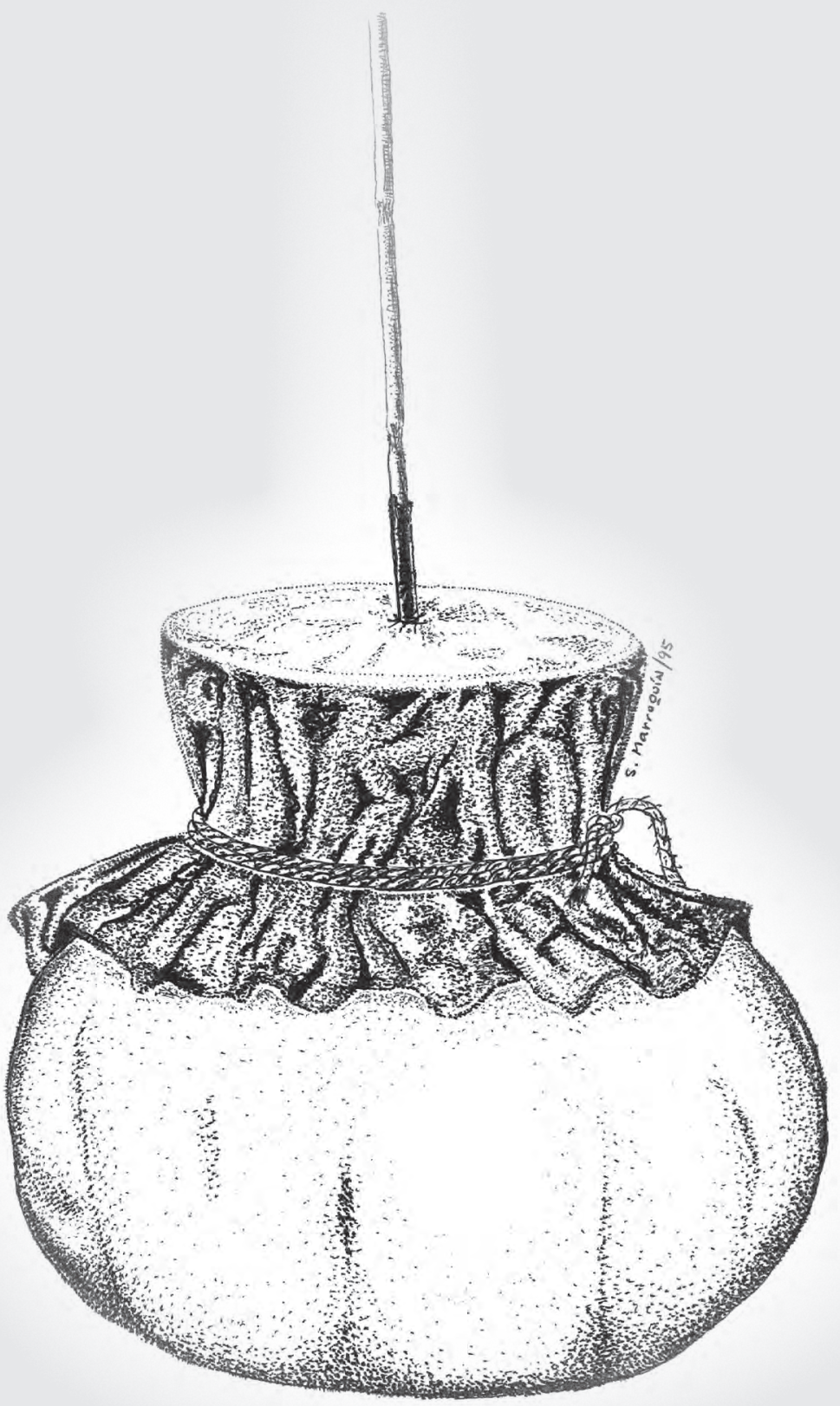

Juque o sacabuche

Salvador Marroquín 